\title{
The treatment of pectus carinatum with the bracing after surgery for congenital heart disease: experience from a single institution
}

De-rong He ( $\square$ 690337467@qq.com )

Fujian Maternity and Child Health Hospital, Affiliated Hospital of Fujian Medical University Jing-jing Zhang $\triangle M D$

Fujian Maternity and Child Health Hospital, Affiliated Hospital of Fujian Medical University

Song-ming Hong

Fujian Maternity and Child Health Hospital, Affiliated Hospital of Fujian Medical University Jun-jie Hong

Fujian Maternity and Child Health Hospital, Affiliated Hospital of Fujian Medical University Jin-xi Huang

Fujian Maternity and Child Health Hospital, Affiliated Hospital of Fujian Medical University Hua Cao

Fujian Maternity and Child Health Hospital, Affiliated Hospital of Fujian Medical University

\section{Research Article}

Keywords: Pectus carinatum, external bracing, congenital heart disease, pediatric patient

Posted Date: April 13th, 2021

DOI: https://doi.org/10.21203/rs.3.rs-403731/v1

License: (1) This work is licensed under a Creative Commons Attribution 4.0 International License. Read Full License 


\section{Abstract}

Purpose:Secondary pectus carinatum (PC) after surgery for congenital heart disease(CHD) has its own clinical characteristics.Conservative treatment of $\mathrm{PC}$ with bracing is an attractive alternative to surgical repair.This study was to investigate the effects of the bracing on treating pediatric patients with PC after heart surgery.

Methods:We conducted a retrospective study of all patients who had PC after surgery for CHD with median sternotomy from March 2019 to December 2020.Monthly follow-up with anterior-posterior(AP) width measurements. The size of bracing is designed based on the patient's anterior chest wall.

Result:Twenty four patients (3/2019-12/2020) were conducted into this retrospective study in the clinic,and 22 patients(91.66\%) achieved excellent correction. The twenty four patients were distributed into three stages(stage 1: treated for 0 month,stage 2:treated for 3 months, stage 3: treated for 6 months). We found statistically significant differences in the AP between stage 2 and stage 1 (AP $p<0.01$ ), stage 3 and stage 2(AP $p<0.01$ ). The main side effects were mild subcutaneous hematoma,petechial bleeding and chest tightness.There was no children complicated with hydropericardium or cardiac tamponade.

Conclusion:The bracing has been shown to be a safe and effective approach for the treatment of the pediatric patients with $\mathrm{PC}$ after surgery for CHD.

\section{Introduction}

Sternotomy is usually used in surgery for CHD.The PC is characterized by protrusion of the sternum and costal cartilages. It is the second most common type of chest wall deformity. [i]Respiratory function tests show no significant pathological changes in these children. If accompanied by scoliosis, restricted respiratory dysfunction may be found.[ii],[iii]Pediatric PC patients may have shortness of breath and symptoms of chest pain, especially during exercise. ${ }^{1}$ In addition to the physical symptoms, the deformity can cause cosmetic and psychological problems.During adolescence, the deformity becomes more prominent as the growth rate increases.Some pediatric patients after surgery for CHD usually combined with PC.In the clinic we met some of these pediatric patients with PC secondary to CHD surgery(fig.1).These pediatric patients are temporarily exempt from social and psychological problems.But their parents are very anxious about their chest wall deformity. As the children get older,they may have negative physical self-esteem and poor quality of life.[iv]Presumably, correcting their chest wall deformities improves self-esteem and confidence.[v]Until recently, corrective methods for patients with PC included aggressive surgical interventions in the form of open or modified Ravitch or minimally invasive procedures.[vi]'[vii]['viii]Conservative treatment of PC avoids operative intervention and possible complications, has no scars, and cost less than surgery. ${ }^{8}$ [ix] In many studies, bracing have had very satisfactory results in adolescents. ${ }^{1,6,9},[x]$ But there is no study has examined the the effects of bracing on 
pediatric patients with PC after CHD surgery. The aim of this study was to examine the effectiveness of bracing to correct $\mathrm{PC}$ in pediatric patients secondary to $\mathrm{CHD}$ surgery.

[i] Frey AS, Garcia VF, Brown RL, Inge TH, Ryckman FC, Cohen AP, Durrett G, Azizkhan RG. Nonoperative management of pectus carinatum. J Pediatr Surg. 2006 Jan;41(1):40-5;discussion405.doi:10.1016/j.jpedsurg.2005.10.076. PMID: 16410105.

[ii] Blanco FC, Elliott ST, Sandler AD. Management of congenital chest wall deformities. Semin Plast Surg. 2011 Feb;25(1):107-16. doi: 10.1055/s-0031-1275177. PMID: 22294949; PMCID: PMC3140238.

[iii] Kuhn MA, Nuss D (2011) Pectus deformities. In: Mattei P (ed) Fundamentals of pediatric surgery. Springer, New York, pp 4. 313-322.

[iv] Martinez-Ferro M, Bellia Munzon G, Fraire C, Abdenur C, Chinni E, Strappa B, Ardigo L. Non-surgical treatment of pectus carinatum with the FMF® Dynamic Compressor System. J Vis Surg. 2016 Mar 17;2:57. doi: 10.21037/jovs.2016.02.20. PMID: 29078485; PMCID: PMC5638266.

[v] Lawson ML, Cash TF, Akers R, Vasser E, Burke B, Tabangin M, Welch C, Croitoru DP, Goretsky MJ, Nuss D, Kelly RE Jr. A pilot study of the impact of surgical repair on disease-specific quality of life among patients with pectus excavatum. J Pediatr Surg. 2003 Jun;38(6):916-8. doi: 10.1016/s00223468(03)00123-4. PMID: 12778393.

[vi] Egan JC, DuBois JJ, Morphy M, Samples TL, Lindell B. Compressive orthotics in the treatment of asymmetric pectus carinatum: a preliminary report with an objective radiographic marker. J Pediatr Surg. 2000 Aug;35(8):1183-6. doi: 10.1053/jpsu.2000.8724. PMID: 10945691.

[vii] Martinez-Ferro M, Fraire C. Dynamic compression system for the correction of pectus carinatum. Semin Pediatr Surg 2008;17:194-200.

[viii] Stephenson JT, Du Bois J. Compressive orthotic bracing in the treatment of pectus carinatum: the use of radiographic markers to predict success. J Pediatr Surg 2008;43:1776-80.

[ix] Lee SY, Lee SJ, Jeon CW, Lee CS, Lee KR. Effect of the compressive brace in pectus carinatum. Eur J Cardiothorac Surg. 2008 Jul;34(1):146-9. doi: 10.1016/j.ejcts.2008.04.012. Epub 2008 May 13. PMID: 18479931.

[x] Kravarusic D, Dicken BJ, Dewar R, Harder J, Poncet P, Schneider M, Sigalet DL. The Calgary protocol for bracing of pectus carinatum: a preliminary report. J Pediatr Surg. 2006 May;41(5):923-6. doi: 10.1016/j.jpedsurg.2006.01.058. PMID: 16677884.

\section{Methods}

The study was approved by the Medical Ethics Committee of Fujian Provincial Maternity and Children's Hospital(the date of IRB approval was April 06,2020, the IRB approval number is 2020-KY-039).All of our 
patients were under the age of 18 and we obtained informed consent from the parents. The method of treating for pectus carinatum with bracing is in accordance with guidelines published by the American Paediatric Surgical Association.[i]

\section{Patients}

We conducted a retrospective study of all patients who had PC after surgery for CHD with median sternotomy from March 2019 to December 2020.The exclusion criteria were as following: having a chronic systemic disease, having complex and mixed type chest wall deformity and being unwilling to use orthosis. The indications for intervention with a bracing were as such:failure to meet the operative criteria,being unwilling to surgery,being compression test positive, and having a pressure of correction under 10 per square inch.At the clinic, patients had the option to undergo surgery or bracing therapy.And most of them preferred to chose the conservative treatment.Echocardiograph $\square$ coagulation function and electrocardiograph was routinely performed before the daily application of the bracing to evaluate the patient and exclude cardiac insufficiency.Data collected included the patient's age, height, weight,chest wall measurements, associated features, associated symptoms and medical history.Patient characteristics are shown in table 1.All pediatric patients should be supervised by caregivers at home.Compliance is the key to permanent correction of the pectus carinatum deformity.

Patients wore a snug fitting undershirt under the bracing (fig.2) at all times to prevent skin breakdown.Within the first week, bracing was used for at least $2 \mathrm{~h}$ a day to increase the tolerance of the chest wall.The use time was gradually increased to $8 \mathrm{~h}$ a day at week 2 and increased to $23 \mathrm{~h}$ a day in one month. Patients should be followed up every 3 months according to the schedule.Using bracing for the first time, the patients should be kept in the clinic and observed for at least half an hour.The pressure for initial correction was measured in all patients. We recorded the pressure of bracing. We tried to flatten the protrusion of the sternum and costal cartilages at the first time when the patients' parents decided to start the treatment.If there was chest pain,chest tightness, palpitations or other persistent symptoms,we reduced the pressure.

Because of the outbreak of novel coronavirus 2019,many patients faced travel restrictions.Patients should be continued to be followed to ensure that their chest remains flat.For those patients who had not returned the clinic after 3 months, we contacted them by WeChat(a popular Chinese mobile messenger app).With the help of WeChat,we could communicate with parents more easily and often.

Every time the bracing was adjusted, it should be monitored by the outpatient doctor, and gradually increased the pressure to flatten the protrusion according to the tolerance of the children.If there was chest pain,chest tightness, palpitations or other symptoms, we stopped the treatment immediately.It should be alert for heart damage.Echocardiography could help us to diagnose.Reducing the pressure and the using time could help most of the patients to continue the treatment.

\section{Statistics}


Statistical analysis was performed by using SPSS Statistics(version 25,SPSS Inc., IBM Company,Chicago,IL).The AP at 0 month, 3 months, 6 months were compared by the Friedman rank test, and the differences in the improvements among patients with different ages,sex,or symmetry classifications were compared by the Mann-Whitey $U$ test.A $p$ value less than 0.05 was considered statistically significant.

[i] American_Pediatric_Surgical_Association. Pectus Carinatum Guideline. APSA

Guideline 2012

https://www.eapsa.org/apsa/media/Documents/Pectus_Carinatum_Guideline_080812.pdf.

\section{Results}

Twenty four patients( 6 females, 18 males)aged 35-120 months(median 55.0 months) adopted the device and were followed up regularly.The daily application of the bracing ranged from $2 \mathrm{~h}$ to $23 \mathrm{~h}$ (average 19.5h). The twenty four patients were distributed into three stages(stage 1: treated for 0 month,stage 2: treated for 3 months, stage 3: treated for 6 months). We found statistically significant differences in the AP between stage 2 and stage1(AP $p<0.01$ ), stage 3 and stage 2(AP $p<0.01$ ). The most common side effects were mild petechial bleeding (16.7\%), thoracalgia (12.5\%), Shortness of breath $(12.5 \%)$ and palpitation (8.3\%).

\section{Discussion}

The pediatric patients included in this study underwent median sternotomy after heart surgery had its own clinical characteristics.First,patients' chest wall is flexible.We could use less pressure to flatten the raised sternum.Second,steel wire was used to suture the sternum after heart surgery.At the end of an operation, the sternal wires are tightened by twisting the two ends together, and then the wires are bent over such that the tips of the wires are directed away from the skin. We could palpable fixation wire locally on the chest wall for some patients.In the process of brace compression,the wire increased skin wear, resulting in local skin swelling, bleeding, pain and other complications. Third,the patients had surgical scars on the anterior median chest wall.Some children were with scar constitution(Fig 3).In the process of brace pressure,the scar were tougher than the surrounding tissue, which would increase the discomfort of children and reduce compliance.These patients were more easily to make skin damage and even bleeding during brace compression.

Our aim is to learn the effects of bracing in the treatment of those patients with PC after CHD surgery. The effect of steel wire on the formation of PC patients remains to be further studied. Whether removing the steel wire has positive effects on the treatment of PC remained to be demonstrated.Because our young patients' chest wall are flexible,these pediatric patients may require longer periods of maintenance bracing.We advise these patients to brace for a few hours a day after achieving satisfactory outcome. 
Echo tests show heart compression and strain in patients with PE, potentially warranting surgical repair with the Nuss procedure.[i] [ii] Because PC is not physically compressing the chest, cardiac evaluation is infrequently considered.However, in this study we also payed attention to the effects of braces on cardiac function.All the 24 children included in the study were regularly followed up by outpatient cardiac surgeons after heart surgery.Reexamination of echocardiography and electrocardiogram showed that the heart function were well.

In 2 cases,subcutaneous fixed wire in the middle of the anterior chest wall protrusion were obvious.We could palpate the wire clearly. Therefore, during brace treatment,we intentionally added a small pad to reduce friction and avoid skin lesions.

Surgical scars were obvious in the middle of chest wall in 5 patients. In the process of brace treatment,we also added a small piece of cotton pad to the scar to reduce friction and avoid skin lesions. Due to the presence of scar,the anterior chest wall discomfort was more obvious at the beginning of brace therapy in these children.However,after 1 month of adaptation,the scar became flatter and the children gradually tolerated the brace therapy.

We generally recommend that children start brace therapy when the weather is cool. So the children will wear more clothes. This can reduce skin problems caused by excessive sweating in children.At the same time, the cotton-padded clothes under the support can better protect the skin of children. In summer,because of the hot weather,we advised that children wear braces and stay in an air-conditioned room.

Kravarusic et al ${ }^{11}$ reported significant improvement in subjective appearance was observed in patients who wore a compression orthosis for 23 hours daily.Colazza et al[iii] detected that the patients were satisfied with the chest wall appearance after bracing treatment and their self-esteem increased.In another study, Thaker et al[iv] investigated patients perception via a nonstandardized questionnaire.They concluded that patients improved self-esteem and satisfaction with their chest wall chest wall appearance.Sesia et al[v] advised that the lateral expansion of the chest should be always considered, allowing breathing and chest expansion due to AP compression forces and natural growth.

In addition to orthosis, exercise should also be carried out to provide a better correction of the deformity of PC patients. If the bracing treatment fails, surgical repair is still a good choice.[vi]Surgical correction is often used in the most severe cases.Patients with mild or moderate PC are usually do not undergo surgical correction.[vii]Lee et al reported that skeletal maturity affects the correction of the deformity. [viii]Emil et al[ix] reported that older age, asymmetry and smaller first drop in pressure of treatment was associated with failure and longer orthosis use.

\section{Limitations}

This study has the following limitations.First the compliance of the pediatric patients and the parents are different.Second,AP may be influenced by fat thickness during the scanning process.Factors that may 
influence the outcome of correction include skeletal maturation,patient growth,and flexibility of the chest wall.Further research is needed for long-term follow-up.

[i] Jaroszewski DE, Warsame TA, Chandrasekaran K, Chaliki H. Right ventricular compression observed in echocardiography from pectus excavatum deformity. J Cardiovasc Ultrasound. 2011 Dec;19(4):192-5. doi: 10.4250/jcu.2011.19.4.192. Epub 2011 Dec 27. PMID: 22259662; PMCID: PMC3259543.

[ii] Oezcan S, Attenhofer Jost CH, Pfyffer M, Kellenberger C, Jenni R, Binggeli C, Faeh-Gunz A, Seifert B, Scharf C, Kretschmar O, Valsangiacomo Buechel ER. Pectus excavatum: echocardiography and cardiac MRI reveal frequent pericardial effusion and right-sided heart anomalies. Eur Heart J Cardiovasc Imaging. 2012 Aug;13(8):673-9. doi: 10.1093/ehjci/jer284. Epub 2012 Jan 31. PMID: 22298154.

[iii] Colozza S, Bütter A. Bracing in pediatric patients with pectus carinatum is effective and improves quality of life. J Pediatr Surg. 2013 May;48(5):1055-9. doi: 10.1016/j.jpedsurg.2013.02.028. PMID: 23701782.

[iv] Thaker S, Anderson M, Fezio J, Rader C, Misra MV. Pectus Carinatum: Factors That Contribute to Success and Failure of Nonoperative Treatment. Conn Med. 2017 Apr;81(4):203-208. PMID: 29714404.

[v] Sesia SB, Holland-Cunz S, Häcker FM. Dynamic Compression System: An Effective Nonoperative Treatment for Pectus Carinatum: A Single Center Experience in Basel, Switzerland. Eur J Pediatr Surg. 2016 Dec;26(6):481-486. doi: 10.1055/s-0035-1570758. Epub 2016 Jan 8. PMID: 26745521.

[vi] Ware JE Jr, Sherbourne CD. The MOS 36-item short-form health survey (SF-36). I. Conceptual framework and item selection. Med Care. 1992 Jun;30(6):473-83. PMID: 1593914.

[vii] Kang DY, Jung J, Chung S, Cho J, Lee S. Factors affecting patient compliance with compressive brace therapy for pectus carinatum. Interact Cardiovasc Thorac Surg. 2014 Dec;19(6):900-3. doi: 10.1093/icvts/ivu280. Epub 2014 Aug 27. PMID: 25164133.

[viii] Lee RT, Moorman S, Schneider M, Sigalet DL. Bracing is an effective therapy for pectus carinatum: interim results. J Pediatr Surg. 2013 Jan;48(1):184-90. doi: 10.1016/j.jpedsurg.2012.10.037. PMID: 23331813.

[ix] Emil S, Sévigny M, Montpetit K, Baird R, Laberge JM, Goyette J, Finlay I, Courchesne G. Success and duration of dynamic bracing for pectus carinatum: A four-year prospective study. J Pediatr Surg. 2017 Jan;52(1):124-129. doi: 10.1016/j.jpedsurg.2016.10.032. Epub 2016 Oct 27. PMID: 27836367.

\section{Conclusion}

In conclusion,bracing in PC patients after CHD is effective with close follow-up.Successful bracing treatment significantly improves chest appearance and self-esteem of pediatric PC patients.Considering 
the noninvasive, minimal discomfort and high patient satisfactions, we believe that bracing treatment is an effective first-line treatment for many PC patients after CHD.

\section{References}

1. Frey AS, Garcia VF, Brown RL, Inge TH, Ryckman FC, Cohen AP, Durrett G, Azizkhan RG. Nonoperative management of pectus carinatum. J Pediatr Surg. 2006 Jan;41(1):40-5;discussion40-

5.doi:10.1016/j.jpedsurg.2005.10.076. PMID: 16410105.

2. Blanco FC, Elliott ST, Sandler AD. Management of congenital chest wall deformities. Semin Plast Surg. 2011 Feb;25(1):107-16. doi: 10.1055/s-0031-1275177. PMID: 22294949; PMCID:

PMC3140238.

3. Kuhn MA, Nuss D (2011) Pectus deformities. In: Mattei P (ed) Fundamentals of pediatric surgery. Springer, New York, pp 4. 313-322.

4. Martinez-Ferro M, Bellia Munzon G, Fraire C, Abdenur C, Chinni E, Strappa B, Ardigo L. Non-surgical treatment of pectus carinatum with the FMF® Dynamic Compressor System. J Vis Surg. 2016 Mar 17;2:57. doi: 10.21037/jovs.2016.02.20. PMID: 29078485; PMCID: PMC5638266.

5. Lawson ML, Cash TF, Akers R, Vasser E, Burke B, Tabangin M, Welch C, Croitoru DP, Goretsky MJ, Nuss D, Kelly RE Jr. A pilot study of the impact of surgical repair on disease-specific quality of life among patients with pectus excavatum. J Pediatr Surg. 2003 Jun;38(6):916-8. doi: 10.1016/s00223468(03)00123-4. PMID: 12778393.

6. Egan JC, DuBois JJ, Morphy M, Samples TL, Lindell B. Compressive orthotics in the treatment of asymmetric pectus carinatum: a preliminary report with an objective radiographic marker. J Pediatr Surg. 2000 Aug;35(8):1183-6. doi: 10.1053/jpsu.2000.8724. PMID: 10945691.

7. Martinez-Ferro M, Fraire C. Dynamic compression system for the correction of pectus carinatum. Semin Pediatr Surg 2008;17:194-200.

8. Stephenson JT, Du Bois J. Compressive orthotic bracing in the treatment of pectus carinatum: the use of radiographic markers to predict success. J Pediatr Surg 2008;43:1776-80.

9. Lee SY, Lee SJ, Jeon CW, Lee CS, Lee KR. Effect of the compressive brace in pectus carinatum. Eur J Cardiothorac Surg. 2008 Jul;34(1):146-9. doi: 10.1016/j.ejcts.2008.04.012. Epub 2008 May 13. PMID: 18479931.

10. Kravarusic D, Dicken BJ, Dewar R, Harder J, Poncet P, Schneider M, Sigalet DL. The Calgary protocol for bracing of pectus carinatum: a preliminary report. J Pediatr Surg. 2006 May;41(5):923-6. doi: 10.1016/j.jpedsurg.2006.01.058. PMID: 16677884.

11. American_Pediatric_Surgical_Association.Pectus Carinatum Guideline. APSA

12. Guideline 2012 https://www.eapsa.org/apsa/media/Documents/Pectus_Carinatum_Guideline_080812.pdf.

13. Jaroszewski DE, Warsame TA, Chandrasekaran K, Chaliki H. Right ventricular compression observed in echocardiography from pectus excavatum deformity. J Cardiovasc Ultrasound. 2011 
Dec;19(4):192-5. doi: 10.4250/jcu.2011.19.4.192. Epub 2011 Dec 27. PMID: 22259662; PMCID: PMC3259543.

14. Oezcan S, Attenhofer Jost CH, Pfyffer M, Kellenberger C, Jenni R, Binggeli C, Faeh-Gunz A, Seifert B, Scharf C, Kretschmar O, Valsangiacomo Buechel ER. Pectus excavatum: echocardiography and cardiac MRI reveal frequent pericardial effusion and right-sided heart anomalies. Eur Heart $\mathrm{J}$ Cardiovasc Imaging. 2012 Aug;13(8):673-9. doi: 10.1093/ehjci/jer284. Epub 2012 Jan 31. PMID: 22298154.

15. Colozza S, Bütter A. Bracing in pediatric patients with pectus carinatum is effective and improves quality of life. J Pediatr Surg. 2013 May;48(5):1055-9. doi: 10.1016/j.jpedsurg.2013.02.028. PMID: 23701782.

16. Thaker S, Anderson M, Fezio J, Rader C, Misra MV. Pectus Carinatum: Factors That Contribute to Success and Failure of Nonoperative Treatment. Conn Med. 2017 Apr;81(4):203-208. PMID: 29714404.

17. Sesia SB, Holland-Cunz S, Häcker FM. Dynamic Compression System: An Effective Nonoperative Treatment for Pectus Carinatum: A Single Center Experience in Basel, Switzerland. Eur J Pediatr Surg. 2016 Dec;26(6):481-486. doi: 10.1055/s-0035-1570758. Epub 2016 Jan 8. PMID: 26745521.

18. Ware JE Jr, Sherbourne CD. The MOS 36-item short-form health survey (SF-36). I. Conceptual framework and item selection. Med Care. 1992 Jun;30(6):473-83. PMID: 1593914.

19. Kang DY, Jung J, Chung S, Cho J, Lee S. Factors affecting patient compliance with compressive brace therapy for pectus carinatum. Interact Cardiovasc Thorac Surg. 2014 Dec;19(6):900-3. doi: 10.1093/icvts/ivu280. Epub 2014 Aug 27. PMID: 25164133.

20. Lee RT, Moorman S, Schneider M, Sigalet DL. Bracing is an effective therapy for pectus carinatum: interim results. J Pediatr Surg. 2013 Jan;48(1):184-90. doi: 10.1016/j.jpedsurg.2012.10.037. PMID: 23331813.

21. Emil S, Sévigny M, Montpetit K, Baird R, Laberge JM, Goyette J, Finlay I, Courchesne G. Success and duration of dynamic bracing for pectus carinatum: A four-year prospective study. J Pediatr Surg. 2017 Jan;52(1):124-129. doi: 10.1016/j.jpedsurg.2016.10.032. Epub 2016 Oct 27. PMID: 27836367.

\section{Figures}




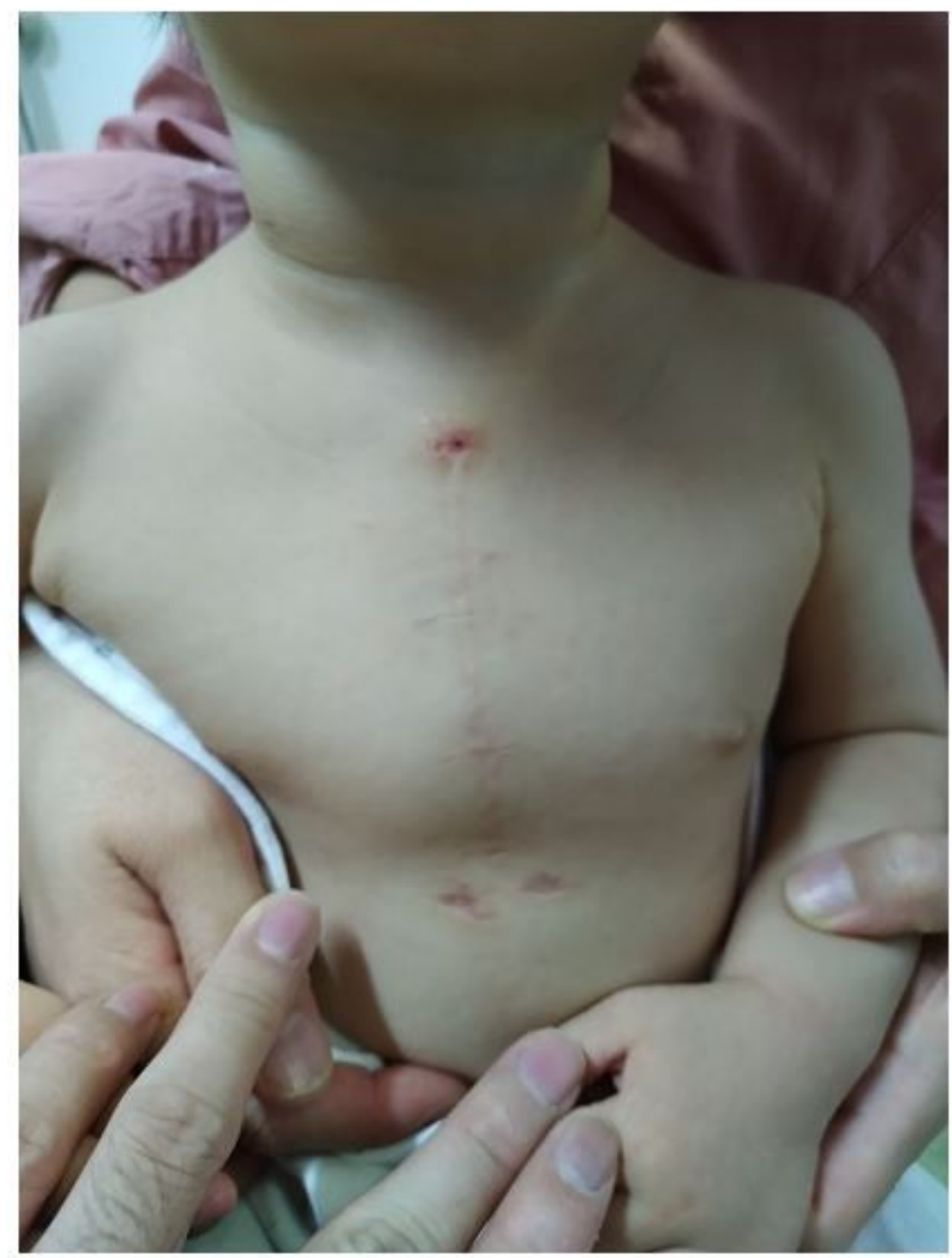

Figure 1

Patient before treatment. 


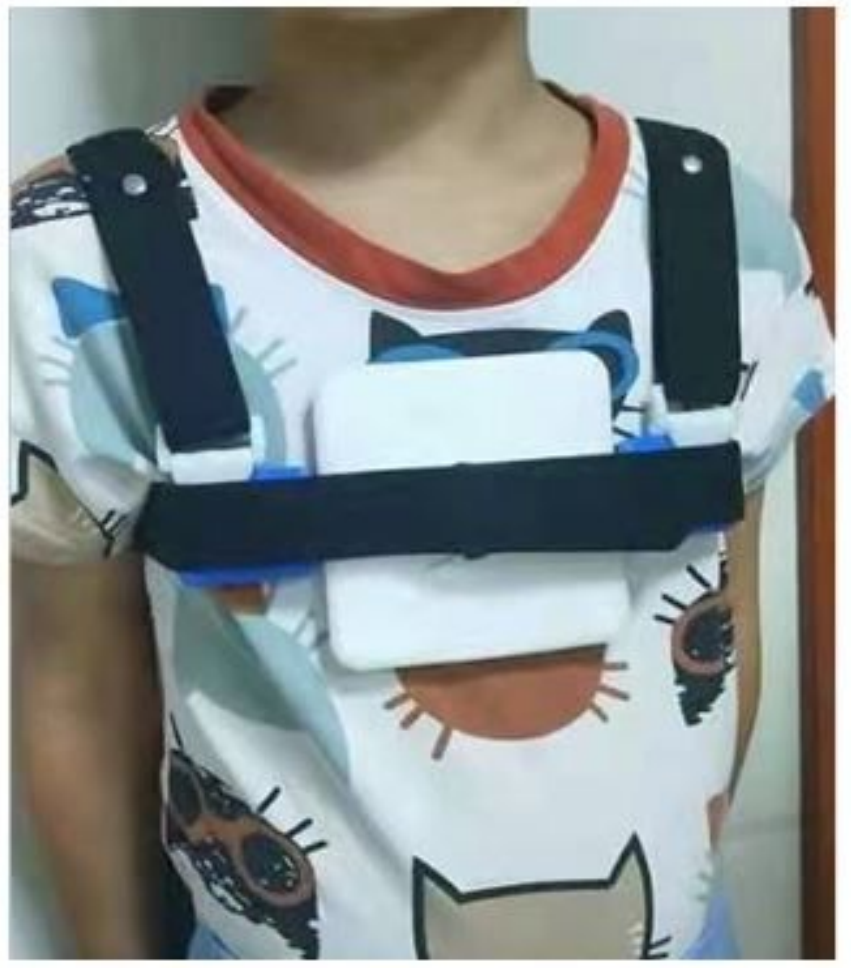

Figure 2

Patient wearing the external brace. 


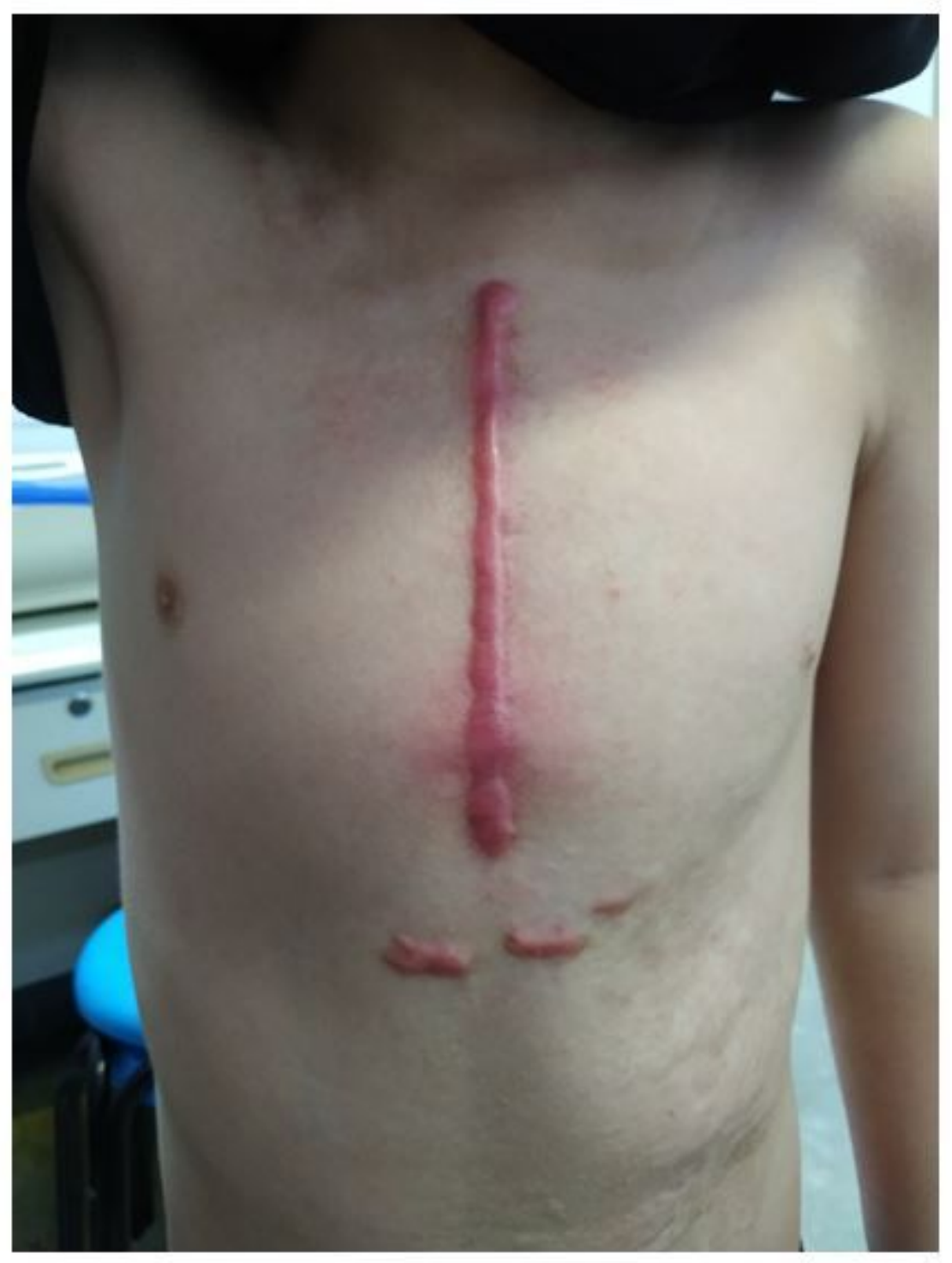

Figure 3

Patient with scar constitution.

\section{Supplementary Files}

This is a list of supplementary files associated with this preprint. Click to download.

- file.doc 